2 Speight ANP. Is childhood asthma being underdiagnosed and undertreated? Br Med F 1978; ii :231-2.

${ }^{3}$ Anderson HR, Bailey PA, Cooper JS, Palmer JC. Influence of morbidity, illness label, and social, family, and health service factors on drug treatment of childhood asthma. Lancet 1981 ;ii:1030-2.

' Anonymous. Asthma-a challenge for general practice. 7 R Coll Gen Pract $1981 ; 31: 323-4$

${ }^{5}$ Williams H, McNicol KN. Prevalence, natural history, and relationship of wheezy bronchitis and asthma in children. An epidemiological study. Br Med f 1969;iv:321-5.
B Sibbald B, Horn MEC, Gregg I. A family study of the genetic basis of asthma and wheezy bronchitis. Arch Dis Child 1980;55:354-7.

${ }^{7}$ Lenney W, Milner AD. Recurrent wheeze in the preschool child. Arch Dis Child 1978;53:468-73.

${ }^{8}$ Gregg I. The role of viral infections in asthma and bronchitis. In: Proudfoot AT, ed. Symposium: viral diseases. Edinburgh: Royal College of Physicians of Edinburgh, 1975. (Publication No 46.)

9 Taussig LM, Smith SM, Blumefeld R. Chronic bronchitis in childhood: what is it? Pediatrics $1981 ; 67: 1-5$

(Accepted 9 February 1983)

\title{
Prevalence and spectrum of asthma in childhood
}

\author{
D A LEE, N R WINSLOW, A N P SPEIGHT, E N HEY
}

\begin{abstract}
All the 7 year old schoolchildren in North Tyneside were screened for wheeze with a questionnaire followed by selective clinical assessment: $9 \cdot 3 \%$ of the children had had episodic wheeze within the past year and all those followed up subsequently responded to one or more of the drugs used for asthma. A further $1.8 \%$ had had similar symptoms since starting school, though they had not wheezed in the past year. Frequency of symptoms in the $11 \%$ of children with features of asthma varied widely and correlated with bronchial reactivity on histamine challenge, but it was not possible to separate children with frequent wheeze from asymptomatic controls by their response to histamine.
\end{abstract}

It was concluded that all these wheezy children had symptoms of a common basic disorder and that they should all be treated as asthmatic.

\section{Introduction}

Estimates of the prevalence of asthma in childhood vary widely. ${ }^{\prime}$ Some authors report point prevalence (or the number of children currently experiencing symptoms), while others report cumulative prevalence. More important, some authors include only children diagnosed as having asthma, whereas others include children with recurrent episodic wheeze who have never been given a specific diagnosis. Some authors include children having had a single episode of wheeze; others include only children who have had several attacks of indeterminate duration and severity. Many have accepted an uncorroborated parental report of wheeze, but we find that some parents confuse croup, stridor, dyspnoea, and nocturnal snoring with wheeze. We have sought a way around this confusion by seeing each child individually and monitoring the response to bronchodilators in a population sample of 7 year olds currently experiencing episodic wheeze.

Preston Hospital, North Shields NE29 0LR

D A LEE, MB, BS, paediatric research registrar

N R WINSLOW, BMEDSCI, medical student

Children's Clinic, Royal Victoria Infirmary, Newcastle upon Tyne NE1 4LP

A N P SPEIGHT, MRCP, first assistant in child health

E N HEY, FRCP, paediatrician

Correspondence to: Dr E N Hey, Princess Mary Maternity Hospital, Great North Road, Newcastle upon Tyne NE2 3BD.

\section{Subjects and methods}

Screening-All children in the third year of school in North Tyneside were screened for "chest trouble" by questionnaire during the first eight months of 1979, when they were about 7 years old. The questionnaire sought to uncover symptoms, rather than diagnoses, and the terms asthma and wheezy bronchitis were not used. The key question was, "Has your child ever had attacks of wheezing ?" There were also three supplementary questions about recurrent nocturnal cough, sudden shortness of breath, and wheezing or shortness of breath on exercise. Parents were told that wheezing meant noisy breathing with a whistling quality coming from the chest and not just the throat and asked to answer "yes," "no," or "not sure" to each of the questions. Independent validation of the questionnaire in 450 children aged 7-8 years confirmed that a positive response to the questions on spontaneous wheeze and cough and wheeze on exercise identified all the children with wheeze in the past year and all but one of the children with wheeze since school entry. It identified only about two fifths of children who had stopped wheezing after the first two or three years of life, but we expected this because the covering letter made it clear that the survey was primarily concerned to identify children with current chest trouble.

Assessment-Twoout of three of the children who reported symptoms since starting school at 5 were selected at random, and $88 \%$ of these were eventually assessed individually along with 100 control children also selected at random. A full clinical history was taken from each mother and the child subjected to physical examination, basic spirometry with a McDermott spirometer, and a histamine challenge test. Skin tests were not performed but specific questions were asked to determine whether the child had any other evidence of an atopic tendency. The findings were discussed with the parents after the lung function and histamine challenge tests were complete. The general practitioner was also fully briefed on the outcome of the examination.

Histamine challenge tests were performed in the presence of a parent by someone who had not been told about the child's medical history. Doubling concentrations of histamine acid phosphate were offered until there was more than a $20 \%$ fall in forced expiratory volume in one second three minutes after taking five maximum inspiratory breaths of the nebulised histamine over 15-30 seconds. ${ }^{2}$ That the fall was real was then confirmed by immediately reversing it with nebulised salbutamol. The maximum concentration used contained $16 \mathrm{~g}$ histamine acid phosphate per litre. No child developed any respiratory distress as a result of this test procedure and only one became tearful for a brief period.

Follow $u p$-In 38 cases where there remained any doubt about the diagnosis or the efficacy of current treatment we obtained the consent of the general practitioner to follow up the child at home, using a diary card and peak flow meter, until it was established that the child had a condition that responded satisfactorily to bronchodilator drugs, inhaled cromoglycate, or beclomethasone. Sixty other children who had not been diagnosed as having asthma before the survey were also reassessed after a year by a social worker previously unconnected with the survey. Forty families were selected at random and interviewed to determine how the family had reacted to being told that their child had asthma. These and a further 20 families who had a child with 
infrequent wheeze (two to six episodes a year) were also seen to assess how the child had responded to treatment.

Approval of study-The survey and test procedures were approved by the health authority's ethical committee and the local medical committee.

\section{Results}

\section{QUESTIONNAIRE}

More than $99 \%$ of the 2700 questionnaires were returned, and $14.8 \%$ of all the children were recorded as having a possible history of wheeze since beginning school. Only $81 \%$ of the children reported as having "definite" wheeze and $57 \%$ of those with "possible" wheeze since school entry, however, were finally accepted as having a convincing history of episodic airways obstruction characterised by wheeze or breathlessness since school entry and therefore classified as having asthma.

Over $96 \%$ of the children were identified by the single key question on wheeze, but two children with recurrent symptoms were identified only by the question on wheeze on exercise, and a few children with exercise induced bronchospasm may have been overlooked as we discounted episodes lasting less than an hour. Five children with occasional symptoms or a history of wheeze were identified only by the other supplementary questions or because of spontaneous parental comment on the bottom of the questionnaire.

\section{PREVALENCE OF ASTHMA}

A total of 150 children (representing $9.3 \%$ of the population) were identified as having had symptoms of asthma in the year before the survey. Only 19 of the families knew that they had a child with asthma, ${ }^{3}$ but we used this term to describe all the 7 year olds identified as wheezing, irrespective of the frequency of symptoms, nature of the precipitating factor, or response to histamine challenge. Subsequent follow up provided strong support for this approach. Eighty nine of the 129 children with current symptoms who had not previously been labelled as having asthma were followed up in the research clinic or interviewed in their homes one year later. Two families reported no further wheeze in the year after the survey; all but one of the other families thought that bronchodilator medicine had eased or abolished the child's wheeze and breathlessness, and all wished to continue using the drug during subsequent attacks of "chestiness." Nearly two thirds of the families volunteered that subsequent attacks had responded to bronchodilator treatment much more rapidly than they had to the antibiotics and cough mixtures used earlier.

Twenty nine children $(1 \cdot 8 \%$ of the population) had had symptoms suggestive of asthma since school entry but had not wheezed for more than a year. It was less easy to prove that these children also had a condition responsive to bronchodilator treatment, but this was definitely true of five children who had further wheeze after the survey was over. A further $3.3 \%$ were reported to have wheezed before starting school, but we know from the independent validation study that the way in which the questionnaire was presented underestimated the prevalence of wheeze at that time.

Cough can be a major symptom in children with asthma even in the absence of appreciable wheeze, ${ }^{4}$ but the extent of this problem was not separately documented during the survey. We did, however, find nine children who had never wheezed but who had a troublesome, longstanding cough that responded dramatically to bronchodilators, cromoglycate, or beclomethasone. Several children with milder degrees of the same disorder were almost certainly overlooked. These children $(0.6 \%$ of the population) are not included in the present estimate of the prevalence of asthma because they did not wheeze and we never found any evidence of airway obstruction.

\section{BRONCHIAL CHALLENGE}

Only 18 children were identified as having airways obstruction at rest (forced expiratory volume in one second/forced vital capacity $<72 \%$ ) on the day they were seen for assessment. The histamine challenge test, which is a non-specific measure of bronchial reactivity, confirmed that the children with frequent symptoms had, on average, the most reactive airways (fig). A third of the children with recurrent wheeze failed, nevertheless, to react to the strongest of the 10 solutions of histamine, as did three of the 31 children having more than 12 attacks of asthma a year. Conversely, a third of the asymptomatic control children had a positive test result $(\leqslant 16 \mathrm{~g} / \mathrm{l})$, and some of these responded to very low concentrations of histamine. Children with a history of wheeze since school entry but no symptoms for the past year behaved like children with occasional wheeze. Bronchial reactivity was not assessed in children who reported wheeze ónly before school entry.

\section{SPECTRUM OF SEVERITY}

A history of atopy was discovered in 23 of the 100 asymptomatic control children. Similar features were found in $63 \%$ of the children with a history of wheeze since school entry, the incidence being highest in those who wheezed most often (table). Parents usually had a clear idea of what precipitated most of the episodes of asthma. Wheeze in response to exercise was most noticeable in those with frequent symptoms, as was wheeze provoked by animal dander and house dust. Conversely, parents most often identified infection as a precipitating factor in children who wheezed only occasionally (table). While these beliefs were not necessarily well founded, they were relatively uninfluenced by medical opinion because only a fifth of the children had been labelled as having asthma or wheezy bronchitis at the start of the survey. Children who were thought to wheeze in response to exercise or house dust showed more bronchial lability than those who usually wheezed in response to infection (fig). A quarter (26/97) of the children who were known to wheeze in response to exercise had had their physical activities curtailed because of this.

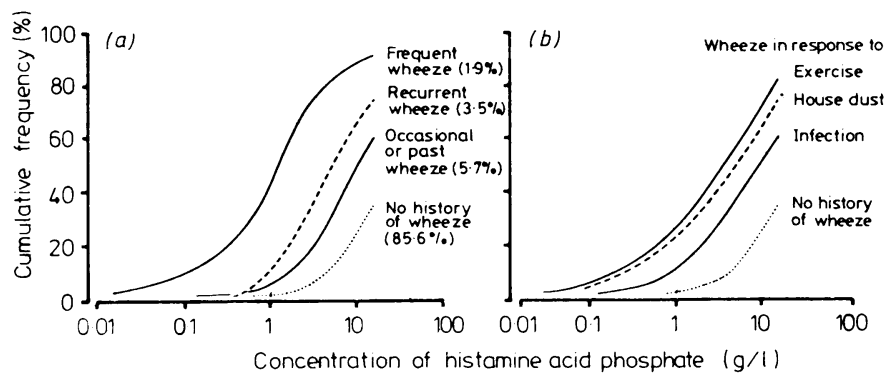

Graded histamine challenge showing proportion of all children in each group exhibiting bronchial reactivity to increasing concentrations of inhaled histamine (cumulative frequency). Sensitivity directly related to frequency of symptoms $(a)$ and more pronounced in children perceived as wheezing in response to exercise and to house dust than in those reported as wheezing in response to infection $(b)$. Symptom frequency graded as in table.

Correlation between frequency of wheeze, other evidence of atopy, and parents' perceptions about factors usually responsible for precipitating wheeze in 7 year olds with history of wheeze since beginning school

\begin{tabular}{|c|c|c|c|c|c|c|c|c|}
\hline \multirow[b]{2}{*}{ Grade } & \multirow[b]{2}{*}{$\begin{array}{l}\text { No of episodes of } \\
\text { wheeze in past year }\end{array}$} & \multirow[b]{2}{*}{ No in sample } & \multirow[b]{2}{*}{$\begin{array}{l}\text { Proportion with } \\
\text { other clinical } \\
\text { atopy } \\
(\%)\end{array}$} & \multicolumn{4}{|c|}{ Proportion thought to wheeze in response to: } & \multirow[b]{2}{*}{$\begin{array}{c}\text { Overall proportion } \\
\text { in school population } \\
(\%)\end{array}$} \\
\hline & & & & $\begin{array}{c}\text { Infection } \\
(\%)\end{array}$ & $\begin{array}{c}\text { House dust } \\
(\%)\end{array}$ & $\begin{array}{c}\text { Other specific } \\
\text { allergens* } \\
(\%)\end{array}$ & $\begin{array}{c}\text { Exercise } \\
(\%)\end{array}$ & \\
\hline $\begin{array}{l}\text { Past } \\
\text { Occasional } \\
\text { Recurrent } \\
\text { Frequent }\end{array}$ & $\begin{array}{c}0 \\
<4 \\
4-12 \\
>12\end{array}$ & $\begin{array}{l}29 \\
63 \\
56 \\
31\end{array}$ & $\begin{array}{l}48 \\
60 \\
66 \\
74\end{array}$ & $\begin{array}{l}64 \\
61 \\
68 \\
35\end{array}$ & $\begin{array}{l}32 \\
48 \\
50 \\
81\end{array}$ & $\begin{array}{r}7 \\
16 \\
19 \\
25\end{array}$ & $\begin{array}{l}29 \\
48 \\
52 \\
94\end{array}$ & $\begin{array}{l}1.8 \\
3.9 \\
3.5 \\
1.9\end{array}$ \\
\hline
\end{tabular}

- Grass pollen or animal dander or both. 
Twice as many boys as girls had a history of wheeze, the male preponderance being particularly noticeable in children with frequent wheeze. We found no correlation between height or weight, social class, or family size and the incidence of asthma or its severity. A quarter of the children had started to wheeze before they were 1 year, and half by the age of 3 . Sixteen per cent had begun wheezing only after starting school. There was no correlation between the age at which symptoms were first noticed and the frequency of symptoms at the age of 7 .

\section{Discussion}

Our finding that $11 \%$ of young children had had episodes of wheeze since school entry agrees with other British surveys. At the start of our survey, however, asthma had been diagnosed in only $1.2 \%$, which is even less than the $2.7 \%$ identified locally by the National Child Development Study ${ }^{5}$ at that age. Other surveys have identified asthma in $1.8-4.8 \%$ of British children, but we believe that all $11 \%$ merited this label because of the way they responded to treatment.

The problem of exactly whom to include in any community survey of asthma remains unsolved. Wheezy bronchitis was long considered to be a separate clinical entity but many studies have now undermined this belief. ${ }^{6}$ Wheeze that does not respond to bronchodilator treatment is so common in early infancy, on the other hand, that wheeze in the first two years of life is best excluded in considering the cumulative prevalence of asthma. Older children with mild symptoms also merge almost imperceptibly into the normal population, and tests of bronchial reactivity have therefore been suggested as a means of deciding whom to include. ${ }^{1}$ Most asthmatics seen in hospital certainly react to lower concentrations of histamine than healthy controls $(<10 \mathrm{~g} / \mathrm{l}),{ }^{7}{ }^{8}$ but many children with mild wheeze responsive to bronchodilator medication are not referred to hospital and a large proportion of these show no undue bronchial sensitivity to histamine (fig). This seriously limits the usefulness of hista- mine challenge as a diagnostic test and casts doubt on the simplistic assumption that children with asthma always respond differently from other children to non-specific bronchial challenge.

However we classify the children identified by our survey, $\widehat{\Omega}$ all had symptoms that were serious enough for the parents to seek medical attention, and all those with current symptoms who were followed up subsequently responded to one or more of the $\mathbb{D}$ drugs used in the management of asthma. It therefore seems simpler to accept that all $11 \%$ had asthma (in one form or another) and to brief the families accordingly. ${ }^{3}$

We are most grateful to Dr Doris Story and her colleagues in the North Tyneside School Health Service and the education authority for their help. Dr Lee was in receipt of a research fellowship from the Northern Regional Health Authority. Fisons Limited made a grant towards the cost of the travel expenses incurred by many of the families during the survey.

\section{References}

1 Gregg I. Epidemiology. In: Clark TJH, Godfrey S, eds. Asthma. London: Chapman and Hall, 1977:214-40.

${ }^{2}$ Chai M, Farr RS, Forelich LA, et al. Standardisation of bronchial inhala- $\infty$ tion challenge procedures. F Allergy Clin Immunol 1975;56:323-7.

3 Speight ANP, Lee DA, Hey EN. Underdiagnosis and undertreatment of $\omega$ asthma in childhood. $\mathrm{Br}$ Med $\mathcal{F} 1983 ; 286: 1255-8$.

4 Cloutier MM, Loughlin GM. Chronic cough in children: a manifestation of airway hyperreactivity. Pediatrics 1981 ;67:6-11.

5 Davie R, Butler NR, Goldstein H. From birth to seven. London : Longman, oु 1972.

${ }^{6}$ Martin AJ, McLennon LA, Landau LI, Phelan PD. The natural history of asthma to adult life. $\mathrm{Br}$ Med $\mathcal{f}$ 1980;280:1397-1400.

7 Mellis CM, Levison $\mathrm{H}$. Bronchial reactivity in cystic fibrosis. Pediatrics $1978 ; 61: 446-50$.

${ }^{8}$ Cockcroft DW, Killian DB, Mellon JJA, Hargreave FE. Bronchial reactivity to inhaled histamine: a method and clinical survey. Clin Allergy 1977;7: 235-43.

(Accepted 9 February 1983)

\section{Clinical curio: Michelin woman in Nepal}

I have recently returned from a trekking holiday to the Annapurna Sanctuary in Nepal. The trek began after three days' acclimatisation in Katmandu ( $1400 \mathrm{~m}$ above sea level). The ascent was gradual, and nine days later we reached a maximum height of $4600 \mathrm{~m}$. During the last few days of the ascent I had felt well but had noticed slight puffiness of the hands and eyes. I remained at this altitude for about six hours and then began a more rapid descent, reaching a height of $2300 \mathrm{~m}$ by the end of the next day. I had not passed any urine since the previous night but was not concerned as I had a high insensible loss from perspiration and diarrhoea. That night, however, I experienced some orthopnoea, and the next morning I woke to find my whole body swollen with a grossly distended abdomen, having not passed urine for 36 hours. I felt well, if somewhat uncomfortable, and after taking an initial dose of $250 \mathrm{mg}$ acetazolamide I continued the descent. Seven hours later I passed a trickle of urine. The dose of acetazolamide was repeated, and this resulted in a most dramatic diuresis over the next 12 hours, with my sleep being disturbed at two hourly intervals throughout the night. The acetazolamide was continued for a further three days, but the oedema did not resolve completely until I returned to England eight days later. Examination on my return showed minimal ankle oedema and a blood pressure of $110 / 65 \mathrm{~mm}$ $\mathrm{Hg}$. There was no proteinuria, and other tests of renal function were normal.

It is likely that I had an unusual form of mountain sickness. The underlying physiological explanation is of abnormal capillary dynamics leading to leakage of fluid from the capillaries into the interstitial space with subsequent oedema formation. ${ }^{1}$ This redistribution of body fluids led to depletion of the circulating volume with resultant prerenal failure and anuria. As would be expected the combined effects of acetazolamide and descent resulted in gradual resolution of symptoms. I would be most interested to hear if any readers have had similar experiences or can offer an alternative explanation.-MONICA PLACZEK, paediatric registrar, London W12 0HS.

' Sutton JR, Lassen N. Pathophysiology of acute mountain sickness and high 15:1045-52.

\section{Clinical curio: warfarin and tonic water}

I have recently seen two patients whose anticoagulant treatment $\frac{0}{3}$ required adjustment after drinking large quantities of tonic water. The first patient, who was taking warfarin for mitral valve disease, had been well stabilised for many months on $6 \mathrm{mg}$ warfarin daily. $N$ Her requirements dropped suddenly to $4 \mathrm{mg}$ or less daily. She told $D$ me that she had started drinking 1-1 $\frac{1}{2}$ litres of tonic water every day; on stopping this her warfarin dose returned to former values. The second patient, the landlady of a public house, also stabilised on $\mathrm{N}$ warfarin had been teetotal since starting warfarin for pulmonary embolism and drank large quantities of water and diluted orange $\sigma$ squash during opening hours. Her warfarin had suddenly had to be halved from $4 \mathrm{mg}$ to $2 \mathrm{mg}$ daily, but nevertheless the British corrected $\frac{\bar{D}}{\mathrm{D}}$ ratio continued to rise and reached 5 over a few days. I then discovered that as a direct consequence of the water dispute and contamination $\square$ of her domestic supply she had switched to drinking tonic water, of $\bar{O}$ which she consumed over 2 litres a day. In neither patient had there $\overrightarrow{\mathbb{D}}$ been any intercurrent illness, additional drug treatment, or alcohol $\frac{\Omega}{\mathbb{D}}$ ingestion.

A leading manufacturer's tonic water contains $79 \mathrm{mg} / \mathrm{l}$ of quinine. In these patients, therefore, the total intake of quinine was about $\Omega$ 80-180 mg daily and seemed to be the only explanation for the 응 change in anticoagulant control. Could this have been another potential health hazard during the water workers' strike?-D J CLARK, consultant haematologist, Chesterfield S42 7SP. 